\title{
The Impact of E-Learning on Teaching Management of Primary Education in Rwanda
}

\author{
Case study: GREENHILLS ACADEMY \& Ecole Primaire Mayange B
}

Mbabazi Ruth

Master of Education Management and Administration of the University of Kigali.

\begin{abstract}
The research conducted to assess the impact of e-Learning on the teaching and learning management in primary education in Rwanda. The researcher must test the validity of the learning using expert validation sheet instruments and limited testing using observation sheets, interview guides, questionnaires and documentation as the main instruments. Data analysis was conducted using descriptive analysis techniques. E-learning is able to generate a high attractiveness and high learning motivation for the students. respondents to give their level of agreement to the statements relate to factors to that influence e-learning teaching management materials, it was revealed that $47.9 \%$ strongly agree that there is management of eLearning in their respective schools, 35.4\% agree with the statement and 16.7\% disagree that in Management of eLearning in your school with mean of 4.58 and a standard deviation of 0.43 . Learner's perspective on learning using e-learning, E-Learning teaching materials, Teacher perspective on teaching using e-Learning. $(\mathrm{F}=7.761, \mathrm{p}$ value $=0.000)$ shows that there is a significant relationship between $\mathrm{p}$ existing Learner's perspective on learning using e-learning, E-Learning teaching materials, Learner's perspective on learning using e-learning.at least one of the slope is not zero.
\end{abstract}

Key words: E-learning, Learning Materials, Management of Primary Education.

\section{Introduction}

Over the past few years, there has been a dramatic advance in information and communication technologies (ICT) infrastructure in Rwanda. The cost of Internet across the country has gone down by more than $50 \%$ due to the roll out of two submarine cables: the Eastern Africa Submarine Cable System and the Southern and Eastern Africa Communication Network (MWTC, 2016). The country has also witnessed a significant decrease in the price of mobile devices to as low as US\$30, allowing many users able to access the Internet via mobile devices (Mtebe\&Kondoro, 2016). Additionally, Internet users have increased from 29\% in 2014 to $40 \%$ in 2016 while mobile penetration has increased to $80 \%$ of the total population by 2017 (TCRA, 2017). Given these developments, educational initiatives directed towards ICT integration in teaching and learning at all levels of education have grown exponentially. Increasingly, ICT integration in education is now being described as a mode of teaching and learning that not only increases students' motivation and deepens understanding of the subject matter but also promotes collaborative and lifelong learning; as well as helping students to think and communicate creatively (Webb, 2005). Studies have also revealed that integrating ICT in education could lead to significant educational and pedagogical outcomes beneficial for both students and teachers (Jimoyiannis, 2008). With these benefits in mind, the government of Rwanda and other stakeholders has taken giant steps in equipping schools with computers, supporting initiatives in installing eLearning platforms, as well as supporting teachers with technological, pedagogical and content knowledge and skills for ICT integration.

Due to COVID 19 pandemic, REB specifies that there are still many practical hurdles for successful widespread use of e-learning in Rwanda. Not only in terms of internet access, internet costs, availability of computers and 
computer skills, but also in terms of attractive and effective content and management of blended teaching methods. Therefore, the findings from this study are expected to promote further research in areas where the research gaps have been identified. Furthermore, the findings will serve as a base for fruitful discussions and dialogues on possible interventions to overcome the most intriguing barriers that hinder eLearning implementation among stakeholders and decision makers in Rwanda.

This chapter therefore, composed of the background to the study, the statement of the problem, the general objective, the specific objectives, the research questions, the research hypotheses, the scope of the study, the significance of the study, and the organisation of the dissertation.

The history of education in Africa can be roughly divided into pre- and post-colonial periods. Since the introduction of formal education to Africa by European colonists, African education, particularly in West and Central Africa, is characterized by both traditional African teachings and European-style schooling systems. Although the quality of education and the quantity of well-equipped schools and teachers has steadily increased since the onset of the colonial period, there are still evident numerous inequalities in the existing educational systems based on region, economic status, and gender.

Considerable progress has been made at the tertiary level through the establishment of the East African National Examination Council which ensures standardization and quality assurance of education in East Africa. Concrete plans are in place for reforms at the lower levels of education and training, through the implementation of a four phased harmonization process: 1. undertaking a regional study to harmonize the goals and philosophies of education, curriculum content, education structures, policies and legal frameworks. 2. Examining the curricula and approaches of delivering teacher training and adult learning programs as well as vocational and technical education in the partner states with a view to identify gaps/overlaps and areas to be harmonized. 3. Developing a relevant curriculum based on the recommendations of the regional study. 4. Focusing on the necessary reforms to be initiated by the partner states in order to implement the harmonized curricula. Learning materials and teachers learning materials play a pivotal role in enhancing the quality of education provided by an instructor, especially in the foundational areas of literacy and numeracy. Cognizant of this, the AU's plan of action aims to improve the availability of reading and mathematics text books for pupils. The pupil textbook ratio for mathematics books in Tanzania is considerably high with 4 pupils sharing a book whilst in Rwanda the ratio is $1: 1$ for both reading and mathematics books.

The quality and availability of teaching and learning materials strongly affect what teachers can do. The application of active learning should not be the sole responsibility of the individual teacher. Changes in teaching and learning methods are likely to mean that the institutions' resources facility will become more important to the quality of teaching.

About Rwanda MINEDUC is demonstrating strong ownership in policy formulation and its implementation in the Sector. MINEDUC holds regular and open consultation processes with various stakeholders including the development partners.

The Government of Rwanda's Education Sector Strategic Plan for 2018/2019 to 2023/24 (ESSP) describes the use of ICT in general as "fundamental" to achieving the socio-economic development outlined in Vision 2063, and its use in education as "critical". An important feature of the Rwandan context is the One Laptop per Child policy espoused in the previous ESSP, which comprised a significant investment in access to ICT.

The Government of Rwanda also intends to develop teachers' ability to use ICT as a tool for learning, and also to provide digital content for pre-primary, primary, and secondary education, enabling multi-mode approaches to education including online and distance learning. Technology in education has significant potential to increase equality of access to and use of education materials. It can enable educational content to be pitched at the right level for each individual student, an important educational principle that is shown by research to be highly effective, and provide better content to children in poor areas than available teachers could provide; it 
can also help less experienced or less competent teachers perform by providing them with teaching materials and tools that can help them deliver better learning outcomes.

E-learning is a form of education that is increasingly being used in higher education in the developed world. However, the take-up and use of e-learning in developing countries is at a preliminary stage. This research deals with e-learning in the context of a developing country taking Rwanda as a research hub. The aim of the study is to describe and understand teachers' beliefs about e-learning in higher education at primary level. Qualitative semi-structured interviews and observations will be used to identify teachers' beliefs about e-learning. The Technological Pedagogical Content Knowledge framework will be used for analyzing the interviews and observations.

Teachers will show varying levels of knowledge about technology, pedagogy and content, as well as varying knowledge levels about different combinations of these three knowledge domains.

The British philosopher Francis Bacon stated, already in the 1600s, "Knowledge is power". The one who has knowledge thereby has power - the unskilled is powerless. But power is also knowledge. The one that has power also has power over the knowledge - power over what knowledge that is to be developed and power over how this knowledge should be used. It concerns power over nature, power over people and their thoughts, power over what is believed to be knowledge (Thurén, 2007, p. 147, translation ours).

ICT was the central to Rwanda's Vision for 2020, and ICT in education is one of the core pillars of the country's National Information and Communications Infrastructure Policy and Plan, adopted in 2000. Tremendous progress has been made since then and the country continues to receive plaudits and support from its development partners. The pace of development of a national ICT infrastructure is remarkable as is the progress within the education system on disseminating computers and providing connectivity and teacher training. Moreover, there is a nationwide effort to provide universal access to both infrastructure and the Internet in order to facilitate ICT in the broadest sense. The Government of Rwanda has set a national goal that the country will achieve middle-income status by 2050 based on an information-rich, knowledge-based society and economy, achieved by modernizing its key sectors using ICT. This vision, developed through a national consultative process that began in 1998, is the driving force for policy development across government ministries, public institutions, and with the country's development partners. Good pedagogical practice has a theory of learning at its core. However, no single best-practice e-learning standard has emerged. This may be unlikely given the range of learning and teaching styles, the potential ways technology can be implemented and the ways in which educational technology itself is changing. Various pedagogical approaches or learning theories may be considered in designing and interacting with e-learning programs.

Social-constructivist: It is a collaborative approach that opens educational content creation to a wider group including the students themselves. The One Laptop per Child Foundation attempted to use a constructivist approach in its project.

Even though, the government of Rwanda has been on the right track as far as harnessing e-learning in all education sectors, there is still a big gap to fill. While most of Rwanda government initiative is upbeat about elearning opportunities, they often ignore the fact that information and communications technology (ICT) infrastructure is expensive and out of reach of many schools (Ajayi, L. 2009). This is mostly evident in villages and areas of the country it also demonstrated the current inequalities in the schools and their management. After the outbreak of Covid 19 pandemic, teaching and learning in Rwanda primary education shifted to Online and it was too heavy on the managements of the schools who tried to put it into action.

The problem is that the future of e-learning is not built on principles of openness inequality with an education in digital competence, yet it should have the policy guiding it function. That's why government took some measures in to actions like TVs and Radio stations to facilitate students acquire learning from home even for 
those in the villages. It has been therefore identified that, there is a pitfall and it's a big challenge on online teaching and learning management in Rwanda. Therefore, the idea of this research has come up to assess the impact of e-learning on teaching and learning management of primary education in Rwanda and find ways of bridging and overcoming the pitfall (Ajayi, L. 2009).

\section{Literature}

E-Learning can be defined as the delivery of technology-supported teaching, based on sound pedagogical teaching practices. "E-Learning is not a passive medium for delivery of content, but is an interactive process between the teacher ,student and school management; facilitated by the benefits that technology has to offer" (Chin Paul, 2004, p. 123). Sloman (2002) defines e-Learning as the delivery of learning or training using electronically based approaches, mainly through the Internet, intranet, extranet, or Web. "E-Learning involves the use of network technologies (such as Internet and business networks) for delivering, supporting, and assessing formal and informal instruction" (Shank \&Sitze, 2004, p. 2).

\section{Experiential learning theory}

Is a cyclical process that capitalizes on the participants' experiences for acquisition of knowledge? This process involves setting goals, thinking, planning, experimentation, reflection, observation, and review. By engaging in these activities, school leaders or managers construct meaning in a way unique to themselves, incorporating the cognitive, emotional, and physical aspects of teaching. "Tell me, and I will forget. Show me, and I may remember. Involve me, and I will understand." (Confucius Circa 450 BC) The Experiential Learning Theory Experiential Learning Theory "provides a holistic model of the learning process and a multi-linear model of adult development" (Baker, Jensen, \& Kolb, 2002, p. 51). In other words, this is an inclusive model of adult learning that intends to explain the complexities of and differences between adult learners within a single framework. The focus of this theory is experience, which serves as the main driving force in learning, as knowledge is constructed through the transformative reflection on one's experience (Baker, Jensen, \& Kolb, 2002). Then leads them to observe and reflect on their experience. After this period of reflective observation, the school leaders then piece their thoughts together to create abstract concepts about what occurred, which will serve as guides for future actions. With these guides in place, the school leaders actively test what they have constructed leading to new experiences and the renewing of the learning cycle (Baker, Jensen, \& Kolb).

\section{Behaviorism}

Behaviorism is primarily concerned with observable and measurable aspects of human behavior on eLearning. In defining behavior, behaviorism theories emphasize changes in behavior that result from stimulus-response associations made by the teachers and learner. An individual selects one response instead of another because of prior conditioning and psychological drives existing at the moment of the action (Parkay\& Hass, 2000). Behaviorists assert that the only behaviors worthy of study are those that can be directly observed; thus, it is actions, rather than thoughts or emotions, which are the legitimate object of study. In assuming that human behavior is learned, behaviorists also hold that all behaviors can also be unlearned, and replaced by new behaviors; that is, when a behavior becomes unacceptable, it can be replaced by an acceptable one. A key element to this theory of learning is the rewarded response. The desired response must be rewarded in order for learning to take place (Parkay\& Hass, 2000). In education management, advocates of behaviorism have effectively adopted this system of rewards and punishments in their classrooms by rewarding desired behaviors and punishing inappropriate ones. Rewards vary, but must be important to the learner in some way. For example, if a teacher wishes to teach the behavior of remaining seated during the class period, the successful student's reward might be checking the teacher's mailbox, running an errand, or being allowed to go to the library to do homework at the end of the class period. As with all teaching methods, success depends on each student's stimulus and response, and on associations made by each learner.

Using behaviorist theory in the classroom can be rewarding for both learners and teachers. Behavioral change occurs for a reason; learners work for things that bring them positive feelings, and for approval from people they admire. They change behaviors to satisfy the desires they have learned to value. They generally avoid 
behaviors they associate with unpleasantness and develop habitual behaviors from those that are repeated often (Parkay\& Hass, 2000). The entire rationale of behavior modification is that most behavior is learned. If behaviors can be learned, then they can also be unlearned or relearned. To improve teaching management for learners in urban and rural primary education in Rwanda, school's modification plans is to implement for their learners. These plans assure success for these students in and out of school.

\section{Cognitive Development Theory}

In Constructionists believe that knowledge is constructed and learning occurs when children create products or artifacts. They assert that learners are more likely to be engaged in learning when these artifacts are personally relevant and meaningful. In studying the cognitive development of children and adolescents, Piaget identified four major stages: sensor motor, preoperational, concrete operational and formal operational .Piaget believed all children pass through these phases to advance to the next level of cognitive development. In each stage, children demonstrate new intellectual abilities and increasingly complex understanding of the world. Stages cannot be "skipped;" intellectual development always follows this sequence. The ages at which children progress through the stages are averages-they vary with the environment and background of individual children. At any given time, a child may exhibit behaviors characteristic of more than one stage. The first stage, sensor motor, begins at birth and lasts until 18 months- 2 years of age. This stage involves the use of motor activity without the use of symbols. Knowledge is limited in this stage, that why school leaders should emphasize based on physical interactions and experiences.

\section{Bloom's Taxonomy}

In 1956, Benjamin Bloom with collaborators Max Englehart, Edward Furst, Walter Hill, and David Krathwohl published a framework for categorizing educational goals: Taxonomy of Educational Objectives. Familiarly known as Taxonomy. The framework elaborated by Bloom and his collaborators consisted of six major categories: Knowledge, Comprehension, Application, Analysis, Synthesis, and Evaluation. The categories after Knowledge were presented as "skills and abilities," with the understanding that knowledge was the necessary precondition for putting these skills and abilities into practice. With the help of school leaders. Each category contains subcategories, all lying along a continuum from simple to complex and concrete to abstract.

Objectives are important to establish in a pedagogical interchange so that teachers and students alike understand the purpose of that interchange.

Organizing objectives helps to clarify objectives for teachers and for students.

Having an organized set of objectives helps school leaders to:

- Plan and deliver appropriate instruction

- Design valid assessment tasks and strategies

- Ensure that instruction and assessment are aligned with the objectives.

\section{Methodology}

The research design may be defined as the arrangement of conditions for collection, and analysis of data in a manner that aims to combine relevance research purposes with the economy in procedure (Kothari, 1999). In this research the researcher used descriptive research design this because the study is deductive but supplemented by some inductive approach. The approach taken because it enables the researcher to use different research strategy and it also enables the researcher to use triangulation (Saunders et al. 2000).

According to Berg (2009), the qualitative method concerned with qualitative phenomena that relate to the quality or kind by using in-depth interviews. It aims at discovering the underlying motives and desires for purpose. This method will help to obtain information that relates to the appreciation feelings of members, ideas; attitudes of members and thereafter to their meaning and interpretation.

According to Berg (2009), the quantitative method is the range of mathematical and statistical techniques use $\mathrm{d}$ to analyze data. This method helped me to present the result on graph, table or chart. Thus it will give to readers a synthetic view about the research work. This method used because there were some analysis of data which asked in collecting data in form of numbers for examples tables and percentages. 
Primary sources of data come straight from the people or works you are researching on and hence direct information one can collect. Therefore, primary sources are first-hand information gathered for the purpose of investigation (Audrey, 1989). Primary data will be through the answers that will be given by respondents as result of having used the questionnaire, observation and interview as instruments of data collection.

Secondary data is the information not gathered for the immediate study at hand but for some other purposes. Secondary data includes library books, strategic plan reports, magazines and other related documents relevant to the topic (Audrey, 1989). Secondary data for this research will be gathered from library books, diverse documentation, internet and strategic plan reports. This study used several methods and techniques for achieving our objectives.

Population is defined as a group of or category of human being, animals and other things that have one or more characteristics in common as a target population of the universe (Kenneth, 1978). The populations focused on are the teachers, and students at Greenhill's Academy and of those at EP Mayange B.

Sample size Sample design is a part of population which is deliberately selected for the purpose of investigation.

A sample is any number of things, people or events less than the total population which is selected for inclusion in the study. Sampling is done by selecting some of the elements in a population; we may draw conclusions about the entire population. Out of a target population of 57 candidates of Green hills academy and E.P Mayange B Rwanda sample size was 50 respondents determined using the slovin's formula

Where:

$$
n=\frac{N}{1+N(e)^{2}}
$$

$\mathrm{n}=$ sample size

$\mathrm{N}=$ total population

$\mathrm{e}=$ margin error

Note: $5 \%$ error tolerance will be used and is more reliable. Thus the sample size of 50 respondents will be obtained as follows:

$$
\text { Where } \mathrm{N}=57, \mathrm{e}=0.05(5 \%)
$$

Therefore:

$$
\begin{aligned}
\mathbf{n} & =\frac{57}{1+57(0.05)^{2}} \\
& =49.8906=50
\end{aligned}
$$

Sampling is the process of systematically selecting representative elements of a population. When these selected elements are examined closely, it is assured that the analysis revealed useful information about the whole population (Kendall \& Kendall, 1992). This is the type of sampling which gives equal chance to every member of the population to be included in the study. This method is sometimes called randomization. One way of using this method is the lottery system in which names are written on piece of paper and placed in a container. The lottery is then drawn; this method helps to reduce biases or prejudices in selecting samples (Sekaran, 2005). In this study, simple random sampling used to select the respondent based on chance.

Sekaran (2005) has indicated that in stratified sampling technique; the researcher first divides the population into subpopulation (strata) on the basis of supplementary information. In this research; after dividing the population into strata; we will draw a simple random sampling for each subpopulation. In this study, Stratified sampling technique will be used to group respondent into different strata. Stratified sampling will be used based on the population of Green hills Academy. 
According Ruane (2005), defined an interview is defined as a face to face conversation between an interviewer and a respondent conducted for the purpose of obtaining information. The research interview will be used and distributed to everyone and the researcher will record and interpret the answers for drawing conclusions about the research problem. Interview is a kind of conversation in which a researcher tries to seek information from interviewee. Thus, it is face-to-face talk or conversation with person from whom you want to get information.

\section{Data Analysis, Presentation And Interpretation}

\section{To compare and contrast e-learning Management in Teaching Materials used in Urban and Rural Primary Education in Rwanda}

Basing on the response on the e-learning management in teaching materials used, the $14.2 \%$ of total respondents strongly agree that they think other schools use the same eLearning materials $16.7 \%$ of total respondents agree with the statement and $50.0 \%$ disagree with the statement with a mean of 4.75 and standard deviation of 4.42 . From the findings in table 4.5, most of respondents agree with the statement relate to the E-Learning teaching management materials and this is supported by the fact that all means of their responses are at very high range which indicates financial support to the they find it easy to use eLearning materials.

In relation to the statement intended to know whether $18.5 \%$ of total respondents strongly agree that does the teaching management of eLearning fit in the e-learning objectives set on student's performance $60.0 \%$ of total respondents agree with the statement and $7.1 \%$ disagree with the statement with a mean of 4.32 and standard deviation of 0.47 . From the findings in table 4.8 , most of respondents agree with the statement relate to find out if they think eLearning is helpful compared to other types regarding the job performance to management of primary schools and this is supported by the fact that all means of their responses are at very high range which indicate the existence of eLearning management affects the school administration of teaching.

\section{To analyze effect of e-learning system on management of teaching methodology being used in urban and} rural primary education in Rwanda.

In this research $52.1 \%$ of total respondents strongly agree that does the teaching management of eLearning fit in the learning objectives set on student's performance and $52.0 \%$ of total respondents agree with the statement with a mean of 4.82 and standard deviation of 0.42

Furthermore, $18.5 \%$ of total respondents strongly agree that does the teaching management of eLearning fit in the e-learning objectives set on student's performance $60.0 \%$ of total respondents agree with the statement and $7.1 \%$ disagree with the statement with a mean of 4.32 and standard deviation of 0.47 . From the findings in table 4.8 , most of respondents agree with the statement relate to find out if they think eLearning is helpful compared to other types regarding the job performance to management of primary schools and this is supported by the fact that all means of their responses are at very high range which indicate the existence of eLearning management affects the school administration of teaching.

\section{Suggesting strategies used by school management on managing the teaching using eLearning in urban and rural primary schools.}

As pointed out by the respondents in table 4.9 in relation to perception of respondents on school managerial strategies in eLearning and what are those strategies, and how are they developed, $32.8 \%$ of the total respondents strongly agree that there is much that can be done to boast eLearning of their respective primary schools, $67.1 \%$ of total respondents agree with the statement with a mean 4.80 and standard deviation of 0.40 .

Lastly regarding the statement which is says that do you have plans for the future use of e-leaning in your school, $60.4 \%$ whereby 29 of total 48 respondents strongly agree with the statement and $38.6 \%$ agree with the statement, with a mean of 4.16 and standard deviation of 0.36 .

\section{Conclusion}

Considering the findings in this research, it is extremely important for the researcher to conclude that respondents of the respective primary schools perceive -learning on teaching management of primary education 
in Rwanda as indicated by a huge response in agreement with the statements that are related to the e-learning management in teaching materials used in urban and rural primary education.it also been indicated that for strategies used by school management on managing the teaching using eLearning in urban and rural primary school in rural areas to successfully be able to make the best from the absorption of the new learning treand they ought to consider relying on the of e-Learning teaching management as all hypothesis in the research confirmed.

\section{Suggestions}

From on the shortcomings of the research, leaders of the respective schools are suggested to provide a clear environment for E-learning to get into the area whenever its necessary because a number of respondents disagreed with this statement and the institution also is suggested to have a smooth environment with to create an environment among its recipients mainly the students, to adjust to the new changes of e-learning.

The researcher suggests top leaders and proprietors of these primary schools to improve the student's empowerment and involvement of the students as fact of e-learning system because some respondents disagree with the statement relate to receiving adequate and reliable training and information concerning the e-learning system of primary the respective primary schools..

\section{Suggestion on further research}

Just as it has been clearly seen in the review of literature, there is a limited amount of research done on the elearning on teaching management of primary education in Rwanda. thus the findings and conclusions in this study serves as a basis for the current and future studies within this very line of managing e-learning education and implementation of the blended learning in Rwandan community.

Proprietors of the respective primary schools at large mainly in Rwanda had not been widely got informed about this existing gap in African particularly Rwandan contexts. This very study therefor, contributes to the knowledge by establishing the fact that eLearning affects the teaching management of primary schools, something that calls further research to be done considering other factors that influence the teaching materials and the methodology being relied on both for the rural and urban schools.

\section{References}

1. Ajayi, L. (2009). An Exploration of Pre-Service Teachers'Perceptions of Learning to Teach while Using Asynchronous Discussion Board. Educational Technology \& Society, 12(2), 86-100.

2. Anderson, J. (2005). IT, e-learning and teacher development. International Education Journal, 5(5), 114.

3. Anderson, T. (2008).The theory and practice of online learning. Athabasca, AB: Athabasca University.

4. Andersson, A. (2010). Learning to learn in e-learning: Constructive practices for development.Örebro University Studies in Informatics 3.

5. Applebee AC, et al. Balancing act: How can universities recognise the scholarly nature of eLearning development for university teachers? 2005;17-25.

6. Bloom, B. S. (1956).Taxonomy of educational objectives handbook: Cognitive domains. NewYork: David McKay.

7. Bosch, C. (2016). Promoting Self-Directed Learning through the Implementation of Cooperative Learning in a Higher Education Blended Learning Environment. Johannesburg, SA: Doctoral dissertation at North-West University.

8. Button D, et al. E-learning; information communication technology (ICT) in nursing education: A review of the literature. Nurse Educ Today. 2013;10:1311-1323.

9. Education Sector Working Group (2012) Forward-Looking Joint Review of the Education Sector Summary Report, April 3rd 2012. (http://www.mofa.go.jp/mofaj/area/rwanda/index.html) In English Abbott,

10. Farrell G, et al. Survey of ICT in education in Africa, Country Reports. Washingoton, DC: InfoDEv/World Bank.2007;2:53. 
11. Hallila LE, et al. Nursing student's use of internet and computer for their education in the College of Nursing. Int J Nurs Clin Pract. 2014;1:1-5.

12. Halverson R and Smith A. How new technologies have (and have not) changed teaching and learning in schools. J Comput Teach Educ. 2009;26:49-54.

13. In Japanese Ogawa, K. (2005) Methods for Analyzing Education and Development Issues. (Kyoiku to kaihatsunikansurubunsekihouhou). In Kuroda, K. and Yokozeki, Y. ed. (2005) Education and International Development: Theory and Practice. (Kokusai kyoikukaihatsuRon - Riron to Jissen). Yuhikaku, Tokyo.

14. Institute of Policy Analysis and Research - Rwanda (IPAR) (2012) IPAR Observatory Report: the Rwanda Education and Skills. Joint Review of the Education Sector (JRES) Meeting, April 3, 2012, in Kigali. (http://www.minecofin.gov.rw/webfm_send/1700)

15. Kelly M, et al. A multi-method study to determine the effectiveness of, and student attitudes to, online instructional videos for teaching clinical nursing skills. Nurse Educ Today. 2009;29:292-300.

16. Kokusai kyoikukaihatsuRon - Riron to Jissen(2017).Yuhikaku, Tokyo. Ministry of Foreign Affairs of Japan (2012a) Country Assistance Policy (Rwanda).

17. Maag M. Nursing students' attitudes towards technology: A national study. Nurse Educ. 2006;31:112118.

18. Ministry of Education (MINEDUC) (2010b) Education Sector Strategic Plan (ESSP) 2010 - 2015. Ministry of Education (MINEDUC) (2010c) 2010 Education Statistics.

19. Ministry of Education, Science, Technology and Scientific Research (2003) Education Sector Policy.Ministry of Education (2007) Special Needs Education Policy.Ministry of Education (MINEDUC) (2008) Nine Years Basic Education, Implementation Fast Track Strategies.

20. Ministry of Finance and Economic Planning (MINECOFIN) (2010) Official Development Assistance Report.(http://www.minecofin.gov.rw/webfm_send/1704) 